\title{
A Theoretical Inference About Ratio Estimation of Population Mean Using Ranked Set Sampling Under Bivariate Normal Distribution
}

\author{
Sinem Tuğba ŞAHIN TEKİN ${ }^{1 *}$, Merve KÖR ${ }^{2}$, Yaprak Arzu ÖZDEMİR ${ }^{3}$ \\ ${ }^{1,3}$ Gazi University, Faculty of Science, Department of Statistics, Besevler, Ankara, Turkey \\ ${ }^{2}$ Republic of Turkey Ministry of Industry and Technology, Ankara, Turkey \\ (ORCID: 0000-0003-3544-8123) (ORCID: 0000-0001-5930-8489) (ORCID: 0000-0003-3752-9744)
}

\begin{abstract}
Ranked set sampling is a sampling technique that uses ranking information when measuring units is difficult or expensive. In this study, ratio estimation of the population mean is considered in the case of units ranking by both auxiliary variable and the variable of interest in ranked set sampling under bivariate normal distribution. We obtained some theoretical inferences about the mean square error of the ratio estimation in this situation in a simple form depending on coefficient of variation. Besides, we made a theoretical comparison of mean square errors by ranking based on auxiliary variable and interested variable. Using this comparison, one can choose which ranking strategy should be utilized by using correlation coefficient and coefficients of variation of interested variable and auxiliary variable in a problem easily. When the coefficients of variation are close to each other and the correlation coefficient is close to one, ranking can be conducted according to any variable. However, when the coefficient of variation of the interested variable is greater than the coefficient of variation of the auxiliary variable and the correlation coefficient between them is small, ranking should be preferred by using the interested variable. The performance of the ratio estimators was compared by a simulation study. The simulation results indicated that the ranked set sampling estimators were more efficient than the simple random sampling estimators for the same sample size and correlation coefficient. A real data example was also given to demonstrate for calculating relative efficiencies.
\end{abstract}

Keywords: Ranked set sampling, Auxiliary variable, Coefficient of variation, Relative efficiency.

\section{İki Değişkenli Normal Dağılım Altında Sıralı Küme Örneklemesi Kullanılarak Yığın Ortalamasının Oran Tahmini için Teorik Bir Çıkarsama}

\begin{abstract}
$\ddot{O} \mathbf{z}$
Sıralı küme örneklemesi, birimleri ölçmenin zor veya pahalı olduğu durumlarda sıralama bilgisini kullanan bir örnekleme tekniğidir. Bu çalışmada, iki değişkenli normal dağılım altında sıralı küme örneklemesinde hem yardımcı değişken hem de ilgilenilen değişkene göre birimlerin sıralaması söz konusu olduğunda yığın ortalamasının oran tahmini dikkate alınmışıı. Bu durumda oran tahmininin hata kare ortalamasına ilişkin değişim katsayısına bağlı bazı teorik çıkarımlar elde edilmiş̧ir. Ayrıca, yardımcı değişken ve ilgilenilen değişkene göre sıralama yapılarak elde edilen ortalama hata karelerin teorik bir karşılaştırması yapılmıştır. Bu karşılaştırma kullanılarak, ele alınan problemde hangi sıralama stratejisinin kullanılması gerektiği korelasyon katsayısına ve ilgilenilen değişken ile yardımcı değişkenin değişim katsayılarına bakılarak kolayca seçilebilir. Değişim katsayıları birbirine yakın ve korelasyon katsayısı bire yakın iken herhangi bir değişkene göre sıralama yapılabilir. Ancak ilgilenilen değiş̧ene ilişkin değişim katsayısı yardımcı değişkene ilişkin değişim katsayısından büyük ve aralarındaki korelasyon katsayısı düşük iken ilgilenilen değişkene göre sıralama yapılması tercih edilmelidir. Oran tahmin edicilerinin performansları simülasyon çalışması ile karşılaştırılmıştır. Simülasyon sonuçları, aynı örnek büyüklüğü ve korelasyon katsayısı için sıralı küme örneklemesi tahmin edicilerinin, basit rastgele örnekleme tahmin edicilerinden daha etkin olduğunu göstermiştir. Göreli etkinliklerin hesaplanmasını göstermek için gerçek veri örneği de sunulmuştur.
\end{abstract}

Anahtar kelimeler: Sıralı küme örneklemesi, Yardımcı değişken, Değişim katsayısı, Göreli etkinlik.

*Corresponding author: sinemsahin@gazi.edu.tr

Received: 13.02.2020, Accepted: 26.09 .2020 


\section{Introduction}

Ranked Set Sampling (RSS) is a technique that is need of in many fields, especially agriculture and environment and widely used in recent years. It can sometimes be quite difficult to the measurement of units in terms of variables of interest. There may not always be enough cost and time for the measurement process. In these cases, using RSS when selecting sample is more benefit than the Simple Random Sampling (SRS) technique in terms of both cost and time.

In RSS, sample is selected at two stages. At the first stage of the sample selection, $m$ random sets of size $m$ are selected from the infinite population and each sample is called as set. Then, the units within each set are ranked with respect to the variable of interest. This ranking is based on such a low level measurement which is inexpensive and can be implemented using prior information, a visual ranking or an auxiliary variable. After then, the smallest unit in the first ordered set and the second smallest unit in the second ordered set is selected respectively. Continuing in this way, till the unit with the largest rank in the $m^{\text {th }}$ ordered set is chosen and all selected units measured in accordance with the interested variable with a high level of measurement convincing the desired sensibility, selecting procedure is continued. The whole process can be repeated $r$ times to supply necessary measurements for inference, in this way, producing $n=m r$ measured units out of $m^{2} r$ selected units. Assuming there is no ranking error, $m r$ measured units are the ranked set sample and this sample is denoted by $\left\{Y_{(i) j} ; i=1,2, \ldots, m, j=1,2, \ldots, r\right\}$. In this way, the unbiased estimator of the population mean is as follow;

$\bar{Y}_{R S S}=\frac{1}{m r} \sum_{i=1}^{m} \sum_{j=1}^{r} Y_{(i) j}$

Dell and Clutter demonstrated that, even if there are ranking errors, $\bar{Y}_{R S S}$ is an unbiased estimator of the population mean and furthermore,

$\frac{\operatorname{Var}\left(\bar{Y}_{S R S}\right)}{\operatorname{Var}\left(\bar{Y}_{R S S}\right)} \geq 1$

where $\bar{Y}_{S R S}$ is the sample mean for SRS with size $n$. If the ranking is not effective, it seems like a random sample and the variance of the methods will be equal [1].

RSS was firstly submitted by McIntyre [2]. He proposed a new estimator to estimate the population mean of pasture and forage yields using RSS. He also demonstrated that an unbiased estimator of the population mean was obtained using RSS with variance less than the one obtained using SRS with equal sample size. Then, the necessary mathematical inferences were obtained by Takahasi and Wakimoto [3]. RSS is also used for obtaining the efficient parameter estimations for different distributions. Some of these studies were performed by Lam et. Al., Sinha et al., Bhoj and Ahsanullah, Ozturk, Tahmasebi and Jafari, Dey et. al., Ozturk and Demirel [4-10]. Besides, statistical inferences in finite population setting using ranked set samples were developed by Ozturk and Kavlak [11].

If there is an auxiliary variable positively related with the variable of interest, the ratio estimator of the population mean can be preferred instead of the general estimator of the population mean given in Eq. (1). In the literature, different ratio estimators were proposed for the population mean under RSS. Samawi and Muttlak studied the used of RSS to estimate the population ratio [12]. Ganeslingam and Ganesh compared RSS versus SRS in the estimation of the population mean and the ratio [13]. Al-Omari et. al. proposed a modified ratio-type estimators of the population mean using extreme RSS [14]. AlOmari et. al. proposed new ratio estimators of the population mean using SRS and RSS methods [15]. Kadılar et. al. proposed a new ratio estimator using RSS [16]. Al-Omari suggested the modified ratio estimators of the population mean and investigated the performance of these estimators according to SRS and median ranked set sampling (MRSS) [17]. Singh et. al. suggested a class of estimators to estimate the population mean using auxiliary variable in RSS [18]. Ozturk considered ratio estimators based on a ranked set sample in a finite population setting, where the sample was constructed either with or without replacement policies [19]. Saini and Kumar proposed ratio estimator by using quartiles of the distribution under SRS and RSS [20]. They also showed that the proposed ratio estimator under RSS is more efficient than SRS by simulation study. Al-Omari and Al-Nasser suggested new estimator for the 
population ratio using a multistage MRSS [21]. They obtained that Multistage MRSS estimators are more efficient than the estimators based on SRS, RSS, and MRSS.

In this study, we obtained a new formula about the mean square error (MSE) of the ratio estimator in RSS under normality assumption. In addition to studies in the literature, expected value and MSE formulas for the ratio estimators were obtained theoretically under bivariate normal distribution. These formulas were derived separately for both variable of interest and auxiliary variable ranking cases. Obtained formulas that contain the expected value of order statistics which is obtained from the standard normal distribution can be easily used in practice. The article was organized as follows: In Section 2, ratio estimators of the population mean was considered in the case of the units ranking by both auxiliary variable and variable of interest in RSS. In section 3, a simulation study was conducted. Numerical example was given in Section 4. Finally, we summarized our results in Section 5.

\section{Ratio Estimators of the Population Mean in RSS}

Let the auxiliary variable be $X$ and variable of interest be $Y$. In this case, the ratio estimator in RSS will be considered in two situations by which the ranking was done according to variable $X$ and the same according to variable $Y$.

\subsection{Ranking according to auxiliary variable $X$}

Assume that $(X, Y)$ has a bivariate normal distribution with parameters $\mu_{X}, \mu_{Y}, \sigma_{X}, \sigma_{Y}$ and correlation coefficient $\rho$ and we can rank on the auxiliary variable $X$. A real measurement of the smallest element of $X$ is taken together with the $Y$ variable associated with the smallest $X$ from the first sample. A real measurement of the second smallest element of $X$ is then taken together with the $Y$ variable associated with the second smallest $X$ from the second sample. This method is continued until the element is chosen for the measurement of the largest rank of $X$ together with the $Y$ associated with the largest $X$ from the $m^{\text {th }}$ sample. The cycle can be repeated $r$ times until $n=m r$ units are measured. In this case, the ranking based on $X$ will be perfect while the ranking according to $Y$ will be erroneous. Then, $\left(Y_{[i]}, X_{(i)}\right)$ is an $i^{\text {th }}$ judgement ordering in the $i^{\text {th }}$ sample for the variable $Y$ and the $i^{\text {th }}$ order statistic in the $i^{\text {th }}$ sample for variable $X$. The ratio estimator of the population ratio $R=\frac{\mu_{y}}{\mu_{x}}$ using RSS when ranking according to variable $X$ is defined as

$r_{R S S(X)}=\frac{\bar{Y}_{R S S(X)}}{\bar{X}_{R S S(X)}}$

where $\bar{Y}_{R S S(X)}=\frac{1}{m r} \sum_{i=1}^{m} \sum_{j=1}^{r} Y_{[i] j}$ and $\bar{X}_{R S S(X)}=\frac{1}{m r} \sum_{i=1}^{m} \sum_{j=1}^{r} X_{(i) j}$ are the sample means of ranking variable $Y$ and auxiliary variable $X$, respectively. The ratio estimator for the population mean is defined as

$\bar{Y}_{r_{R S S(X)}}=r_{R S S(X)} \mu_{x}=\frac{\bar{Y}_{R S S(X)}}{\bar{X}_{R S S(X)}} \mu_{x}$

where $\mu_{x}=E(X)$.

The expected value of $\bar{Y}_{r_{R S S(X)}}$ is defined as

$E\left(\bar{Y}_{r_{R S S(X)}}\right)=\mu_{x} E\left(r_{R S S(X)}\right)=\mu_{x} E\left(R\left(1+e_{0}\right)\left(1+e_{1}\right)^{-1}\right)$,

where $e_{1}=\frac{\bar{X}_{\mathrm{RSS}(X)}}{\mu_{x}}-1$ and $e_{0}=\frac{\bar{Y}_{R S S(X)}}{\mu_{y}}-1$.

By using the Taylor expansion for the first order approximation, we have

$E\left(\bar{Y}_{r_{R S S(X)}}\right) \cong \mu_{x} R E\left(1+e_{0}-e_{1}-e_{0} e_{1}+e_{1}^{2}\right)$, 


$$
=\mu_{x} R\left(1+E\left(e_{1}^{2}\right)-E\left(e_{0} e_{1}\right)\right)
$$

where

$$
\begin{aligned}
& E\left(e_{1}^{2}\right)=E\left(\frac{\left(\bar{X}_{\mathrm{RSS}(X)}-\mu_{x}\right)^{2}}{\mu_{x}{ }^{2}}\right)=\frac{1}{\mu_{x}^{2}} \operatorname{Var}\left(\bar{X}_{\mathrm{RSS}(X)}\right)=\frac{1}{\mu_{x}^{2}} \frac{1}{m r}\left(\sigma_{x}^{2}-\frac{1}{m} \sum_{i=1}^{m} \tau_{x(i)}^{2}\right), \\
& \begin{aligned}
E\left(e_{0} e_{1}\right)= & E\left(\left(\frac{\bar{Y}_{R S S(X)}-\mu_{y}}{\mu_{y}}\right)\left(\frac{\bar{X}_{\mathrm{RSS}(X)}-\mu_{x}}{\mu_{x}}\right)\right)=\frac{1}{\mu_{x} \mu_{y}} E\left(\left(\bar{Y}_{R S S(X)}-\mu_{y}\right)\left(\bar{X}_{\mathrm{RSS}(X)}-\mu_{x}\right)\right), \\
& =\frac{1}{\mu_{x} \mu_{y}} \frac{1}{m r}\left(\sigma_{y x}-\frac{1}{m} \sum_{i=1}^{m} \tau_{y x(i)}\right) .
\end{aligned}
\end{aligned}
$$

The following expected value formula is obtained by using these expressions in their places in

$E\left(\bar{Y}_{r_{R S S(X)}} \cong \mu_{x} R\left[1+\frac{1}{\mu_{x}^{2}} \frac{1}{m r}\left(\sigma_{x}^{2}-\frac{1}{m} \sum_{i=1}^{m} \tau_{x(i)}^{2}\right)-\frac{1}{\mu_{x} \mu_{y}} \frac{1}{m r}\left(\sigma_{y x}-\frac{1}{m} \sum_{i=1}^{m} \tau_{y x(i)}\right)\right]\right.$,

where $\sigma_{x}^{2}=E\left(X-\mu_{x}\right)^{2}, \sigma_{x y}=E\left(X-\mu_{x}\right)\left(Y-\mu_{y}\right)$ is the variance of $X$ and covariance of $X$ and $Y$ variable respectively. Besides, $\tau_{x(i)}^{2}=\left(E\left(X_{(i)}\right)-\mu_{x}\right)^{2}$ and $\tau_{y x(i)}=\left(E\left(X_{(i)}\right)-\mu_{x}\right)\left(E\left(Y_{[i]}\right)-\mu_{y}\right)$.

The MSE of $\bar{Y}_{r_{R S S(X)}}$ is also obtain as similar way to obtained expected value as follows $\operatorname{MSE}\left(\bar{Y}_{r_{R S S(X)}}\right)=\mu_{x}^{2} E\left(r_{R S S(X)}-R\right)^{2}=\mu_{x}^{2} R^{2} E\left(\left(1+e_{0}\right)\left(1+e_{1}\right)^{-1}-1\right)^{2}$.

By using the Taylor expansion for the first order approximation, we have $\operatorname{MSE}\left(\bar{Y}_{r_{R S S(X)}} \cong \mu_{x}^{2} R^{2}\left(E\left(e_{0}^{2}\right)+E\left(e_{1}^{2}\right)-2 E\left(e_{0} e_{1}\right)\right)\right.$,

where

$$
\begin{gathered}
E\left(e_{0}^{2}\right)=E\left(\frac{\left(\bar{Y}_{R S S(X)}-\mu_{y}\right)^{2}}{\mu_{y}^{2}}\right)=\frac{1}{\mu_{y}^{2}} E\left(\bar{Y}_{R S S(X)}-\mu_{y}\right)^{2}=\frac{1}{\mu_{y}^{2}} \operatorname{Var}\left(\bar{Y}_{R S S(X)}\right), \\
\begin{array}{c}
\operatorname{MSE}\left(\bar{Y}_{r_{R S S(X)}} \cong \mu_{x}^{2} \frac{R^{2}}{m r}\left[\frac{\sigma_{x}^{2}}{\mu_{x}^{2}}+\frac{\sigma_{y}^{2}}{\mu_{y}^{2}}-\frac{2 \rho \sigma_{x} \sigma_{y}}{\mu_{x} \mu_{y}}\right]-\mu_{x}^{2} \frac{R^{2}}{m^{2} r}\left[\frac{\sum_{i=1}^{m} \tau_{x(i)}^{2}}{\mu_{x}^{2}}+\frac{\sum_{i=1}^{m} \tau_{y[i]}^{2}}{\mu_{y}^{2}}-\frac{2 \sum_{i=1}^{m} \tau_{y x(i)}}{\mu_{x} \mu_{y}}\right],\right. \\
=\frac{\mu_{y}^{2}}{m r}\left[C_{x}^{2}+C_{y}^{2}-2 \rho C_{x} C_{y}\right]-\frac{\mu_{y}^{2}}{m^{2} r}\left[\frac{\sum_{i=1}^{m} \tau_{x(i)}^{2}}{\mu_{x}^{2}}+\frac{\sum_{i=1}^{m} \tau_{y[i]}^{2}}{\mu_{y}^{2}}-\frac{2 \sum_{i=1}^{m} \tau_{y x(i)}}{\mu_{x} \mu_{y}}\right]
\end{array}
\end{gathered}
$$

where $\sigma_{y}^{2}=E\left(Y-\mu_{y}\right)^{2}, C_{x}=\frac{\sigma_{x}}{\mu_{x}}$ and $C_{y}=\frac{\sigma_{y}}{\mu_{y}}$ are the coefficient of variation of $X$ and $Y$ variables, respectively and $\tau_{y[i]}^{2}=\left(E\left(Y_{[i]}\right)-\mu_{y}\right)^{2}$.

The MSE of the ratio estimator for the population mean under $S R S$ can be defined as $\operatorname{MSE}\left(\bar{Y}_{r_{S R S}} \cong \frac{\mu_{y}^{2}}{m r}\left[C_{x}^{2}+C_{y}^{2}-2 \rho C_{x} C_{y}\right]\right.$

Thus, the $\operatorname{MSE}\left(\bar{Y}_{r_{R S S(X)}}\right)$ given in Eq. (5) can be rewritten as follows

$$
\operatorname{MSE}\left(\bar{Y}_{r_{R S S(X)}}\right) \cong \operatorname{MSE}\left(\bar{Y}_{r_{S R S}}\right)-\frac{\mu_{y}^{2}}{m^{2} r}\left[\frac{\sum_{i=1}^{m} \tau_{x(i)}^{2}}{\mu_{x}^{2}}+\frac{\sum_{i=1}^{m} \tau_{y[i]}^{2}}{\mu_{y}^{2}}-\frac{2 \sum_{i=1}^{m} \tau_{y x(i)}}{\mu_{x} \mu_{y}}\right] .
$$


Theorem 1: The MSE of the ratio estimator for the population mean $\mu_{y}$ in RSS when the ranking according to auxiliary variable $X$ is defined as follows

$\operatorname{MSE}\left(\bar{Y}_{r_{R S S(X)}}\right) \cong \operatorname{MSE}\left(\bar{Y}_{r_{S R S}}\right)-\left(C_{x}-\rho C_{y}\right)^{2} \frac{\mu_{y}^{2}}{m^{2} r} \sum_{i=1}^{m} \alpha_{i: m}^{2}$

where $\alpha_{i: m}$ is the expected value of $i^{\text {th }}$ order statistics $Z_{(i)}$ which is obtained from the sample with size $m$ from the standard normal distribution.

Proof 1: Under the assumption of the linear relationship between $X$ and $Y$, the conditional mean of $Y_{[i]}$ is defined as

$E\left(Y_{[i]} / X_{(i)}\right)=\mu_{y}+\rho \frac{\sigma_{y}}{\sigma_{x}}\left(X_{(i)}-\mu_{x}\right)$.

The mean of $Y_{[i]}$ is obtained as follows [22]

$E\left(E\left(Y_{[i]} / X_{(i)}\right)\right)=E\left(Y_{[i]}\right)=\mu_{y}+\rho \frac{\sigma_{y}}{\sigma_{x}}\left(E\left(X_{(i)}\right)-\mu_{x}\right)$.

Let $Z_{(i)}$ is the $i^{\text {th }}$ order statistic of the sample with size $m$ from the standard normal distribution. Using the expected value of $E\left(Z_{(i)}\right)$

$E\left(Z_{(i)}\right)=\alpha_{i: m}=\frac{E\left(X_{(i)}\right)-\mu_{x}}{\sigma_{x}}$

Eq. (9) is rewritten as follows

$E\left(E\left(Y_{[i]} / X_{(i)}\right)\right)=\mathrm{E}\left(Y_{[i]}\right)=\mu_{y}+\rho \sigma_{y} \alpha_{i: m}$.

When Eq. (7) is considered again, the $M S E$ of $\bar{Y}_{r_{R S S(X)}}$ can be found as follows

$$
\begin{aligned}
\operatorname{MSE}\left(\bar{Y}_{r_{R S S(X)}}\right) & \cong \operatorname{MSE}\left(\bar{Y}_{r_{S R S}}\right)-\frac{\mu_{y}^{2}}{m^{2} r}\left[\frac{\sum_{i=1}^{m} \tau_{x(i)}^{2}}{\mu_{x}^{2}}+\frac{\sum_{i=1}^{m} \tau_{y[i]}^{2}}{\mu_{y}^{2}}-\frac{2 \sum_{i=1}^{m} \tau_{y x(i)}}{\mu_{x} \mu_{y}}\right] \\
& =\operatorname{MSE}\left(\bar{Y}_{r_{S R S}}\right)-\frac{\mu_{y}^{2}}{m^{2} r} \sum_{i=1}^{m}\left(W_{x(i)}-W_{y[i]}\right)^{2}
\end{aligned}
$$

where $W_{x(i)}=\frac{E\left(X_{(i)}\right)-\mu_{x}}{\mu_{x}}$ and $W_{y[i]}=\frac{E\left(Y_{[i]}\right)-\mu_{y}}{\mu_{y}}$.

Using Eqs. (10) and (11), $W_{x(i)}$ and $W_{y[i]}$ are obtained as follows

$W_{y[i]}=\frac{E\left(Y_{[i]}\right)-\mu_{y}}{\mu_{y}}=\frac{\rho \sigma_{y}}{\mu_{y}} \alpha_{i: m}$ and $\quad W_{x(i)}=\frac{E\left(X_{(i)}\right)-\mu_{x}}{\mu_{x}}=\frac{\sigma_{x}}{\mu_{x}} \alpha_{i: m}$

Finally, the following MSE formula given in Theorem 1 is obtained and the proof is completed.

$$
\operatorname{MSE}\left(\bar{Y}_{r_{R S S(X)}}\right) \cong \operatorname{MSE}\left(\bar{Y}_{r_{S R S}}\right)-\left(C_{x}-\rho C_{y}\right)^{2} \frac{\mu_{y}^{2}}{m^{2} r} \sum_{i=1}^{m} \alpha_{i: m}^{2}
$$

As seen in Eq. (13), $\operatorname{MSE}\left(\bar{Y}_{r_{R S S(X)}}\right)$ value varies depending on the exchange $C_{y}, C_{x}$ and $\rho$. As the difference between $C_{y}$ and $\rho C_{x}$ increases, $\operatorname{MSE}\left(\bar{Y}_{r_{R S S(X)}}\right)$ will be smaller than $\operatorname{MSE}\left(\bar{Y}_{r_{S R S}}\right)$. Furthermore, when $C_{y}$ and $C_{x}$ are the same, as $\rho$ is close to $1, \operatorname{MSE}\left(\bar{Y}_{r_{R S S(X)}}\right)$ and $\operatorname{MSE}\left(\bar{Y}_{r_{S R S}}\right)$ values are close to each other. As long as the right side of the Eq.(13) is positive, the $\operatorname{MSE}\left(\bar{Y}_{r_{R S S(X)}}\right)$ will be 
smaller than the $\operatorname{MSE}\left(\bar{Y}_{r_{S R S}}\right)$. Thus, more effective results than those of SRS will be obtained in case of ranking according to $X$.

\subsection{Ranking according to variable of interest $Y$}

In real life applications, units are usually ordered using an auxiliary variable. However, in some cases ordering according to an interested variable can be preferred. Units can be ordered by visual ranking according to interested variable in some environmental studies. Similar to the ranking by auxiliary variable, units are visually ranked within each sample with respect to the variable of interest $Y$. Assume that there is no visual ranking error. In this case, the ranking according to $Y$ will be perfect while the ranking based on $X$ will be erroneous. Therefore, $\left(Y_{(i)}, X_{[i]}\right)$ is the $i^{\text {th }}$ order statistic in the $i^{\text {th }}$ sample for the variable $Y$ and the $i^{\text {th }}$ judgement ordering in the $i^{\text {th }}$ sample for the variable $X$. The ratio estimator using RSS when ranking according to variable $Y$ is defined as

$r_{R S S(Y)}=\frac{\bar{Y}_{R S S(Y)}}{\bar{X}_{R S S(Y)}}$,

where $\bar{Y}_{\mathrm{RSS}(Y)}=\frac{1}{m r} \sum_{i=1}^{m} \sum_{j=1}^{r} Y_{(i) j}$ and $\bar{X}_{R S S(Y)}=\frac{1}{m r} \sum_{i=1}^{m} \sum_{j=1}^{r} X_{[i] j}$ are the sample means of RSS with errors in ranking variable $X$ and with perfect ranking of variable $Y$, respectively. The ratio estimator for the population mean $\mu_{y}$ is defined by

$\bar{Y}_{r_{R S S(Y)}}=r_{R S S(Y)} \mu_{x}=\frac{\bar{Y}_{R S S(Y)}}{\bar{X}_{R S S(Y)}} \mu_{x}$

The expected value and $M S E$ of $\bar{Y}_{r_{R S S(Y)}}$ are obtained as ranking according to variable of interest. The expected value of $\bar{Y}_{r_{R S S(Y)}}$ is defined as

$E\left(\bar{Y}_{r_{R S S(Y)}}\right)=\mu_{x} E\left(r_{R S S(Y)}\right)=\mu_{x} E\left(R\left(1+e_{0}\right)\left(1+e_{1}\right)^{-1}\right)$,

where $e_{1}=\frac{\bar{X}_{\mathrm{RSS}(Y)}}{\mu_{x}}-1$ and $e_{0}=\frac{\bar{Y}_{R S S(Y)}}{\mu_{y}}-1$.

By using the Taylor expansion for the first order approximation, we have

$$
\begin{aligned}
E\left(\bar{Y}_{r_{R S S(Y)}}\right) & \cong \mu_{x} R E\left(1+e_{0}-e_{1}-e_{0} e_{1}+e_{1}^{2}\right) \\
& =\mu_{x} R\left(1+E\left(e_{1}^{2}\right)-E\left(e_{0} e_{1}\right)\right)
\end{aligned}
$$

where

$$
\begin{aligned}
& E\left(e_{1}^{2}\right)=E\left(\frac{\left(\bar{X}_{\mathrm{RSS}(Y)}-\mu_{x}\right)^{2}}{\mu_{x}{ }^{2}}\right)=\frac{1}{\mu_{x}^{2}} \operatorname{Var}\left(\bar{X}_{\mathrm{RSS}(Y)}\right)=\frac{1}{\mu_{x}^{2}} \frac{1}{m r}\left(\sigma_{x}^{2}-\frac{1}{m} \sum_{i=1}^{m} \tau_{x[\mathrm{i}]}^{2}\right), \\
& \begin{aligned}
E\left(e_{0} e_{1}\right)= & E\left(\left(\frac{\bar{Y}_{R S S(Y)}-\mu_{y}}{\mu_{y}}\right)\left(\frac{\bar{X}_{\mathrm{RSS}(Y)}-\mu_{x}}{\mu_{x}}\right)\right)=\frac{1}{\mu_{x} \mu_{y}} E\left(\left(\bar{Y}_{R S S(Y)}-\mu_{y}\right)\left(\bar{X}_{\mathrm{RSS}(Y)}-\mu_{x}\right)\right), \\
& =\frac{1}{\mu_{x} \mu_{y}} \frac{1}{m r}\left(\sigma_{y x}-\frac{1}{m} \sum_{i=1}^{m} \tau_{y x(i)}\right) .
\end{aligned}
\end{aligned}
$$

Thus the expected value is obtained as

$$
E\left(\bar{Y}_{r_{R S S(Y)}}\right) \cong \mu_{Y}\left[1+\frac{1}{\mu_{x}^{2}} \frac{1}{m r}\left(\sigma_{x}^{2}-\frac{1}{m} \sum_{i=1}^{m} \tau_{x[\mathrm{i}]}^{2}\right)-\frac{1}{\mu_{x} \mu_{y}} \frac{1}{m r}\left(\sigma_{x y}-\frac{1}{m} \sum_{i=1}^{m} \tau_{x y(i)}\right)\right],
$$

where $\tau_{x[i]}^{2}=\left(E\left(X_{[i]}\right)-\mu_{x}\right)^{2}$ and $\tau_{x y(i)}=\left(E\left(X_{[i]}\right)-\mu_{x}\right)\left(E\left(Y_{(i)}\right)-\mu_{y}\right)$. 
The MSE of $\bar{Y}_{r_{R S S(Y)}}$ is also obtain as similar way to obtained expected value as follows $\operatorname{MSE}\left(\bar{Y}_{r_{R S S(Y)}}\right)=\mu_{x}^{2} E\left(r_{R S S(\mathrm{Y})}-R\right)^{2}=\mu_{x}^{2} R^{2} E\left(\left(1+e_{0}\right)\left(1+e_{1}\right)^{-1}-1\right)^{2}$.

By using the Taylor expansion for the first order approximation, we have $\operatorname{MSE}\left(\bar{Y}_{r_{R S S(Y)}}\right) \cong \mu_{x}^{2} R^{2}\left(E\left(e_{0}^{2}\right)+E\left(e_{1}^{2}\right)-2 E\left(e_{0} e_{1}\right)\right)$, where $E\left(e_{0}^{2}\right)=E\left(\frac{\left(\bar{Y}_{R S S(Y)}-\mu_{y}\right)^{2}}{\mu_{y}^{2}}\right)=\frac{1}{\mu_{y}^{2}} E\left(\bar{Y}_{R S S(Y)}-\mu_{y}\right)^{2}=\frac{1}{\mu_{y}^{2}} \operatorname{Var}\left(\bar{Y}_{R S S(Y)}\right)$.

By using these definitions, the MSE is given as

$$
\begin{aligned}
\operatorname{MSE}\left(\bar{Y}_{r_{R S S(Y}}\right) & \cong \mu_{x}^{2} \frac{R^{2}}{m r}\left[\frac{\sigma_{x}^{2}}{\mu_{x}^{2}}+\frac{\sigma_{y}^{2}}{\mu_{y}^{2}}-\frac{2 \rho \sigma_{x} \sigma_{y}}{\mu_{x} \mu_{y}}\right]-\mu_{x}^{2} \frac{R^{2}}{m^{2} r}\left[\frac{\sum_{i=1}^{m} \tau_{x[\mathrm{i}]}^{2}}{\mu_{x}^{2}}+\frac{\sum_{i=1}^{m} \tau_{y(i)}^{2}}{\mu_{y}^{2}}-\frac{2 \sum_{i=1}^{m} \tau_{x y(i)}}{\mu_{x} \mu_{y}}\right], \\
& =\frac{\mu_{y}^{2}}{m r}\left[C_{x}^{2}+C_{y}^{2}-2 \rho C_{x} C_{y}\right]-\frac{\mu_{y}^{2}}{m^{2} r}\left[\frac{\sum_{i=1}^{m} \tau_{x[i]}^{2}}{\mu_{x}^{2}}+\frac{\sum_{i=1}^{m} \tau_{y(i)}^{2}}{\mu_{y}^{2}}-\frac{2 \sum_{i=1}^{m} \tau_{x y(i)}}{\mu_{x} \mu_{y}}\right], \\
& =\operatorname{MSE}\left(\bar{Y}_{r_{S R S}}\right)-\frac{\mu_{y}^{2}}{m^{2} r}\left[\frac{\sum_{i=1}^{m} \tau_{x[i]}^{2}}{\mu_{x}^{2}}+\frac{\sum_{i=1}^{m} \tau_{y(i)}^{2}}{\mu_{y}^{2}}-\frac{2 \sum_{i=1}^{m} \tau_{x y(i)}}{\mu_{x} \mu_{y}}\right],
\end{aligned}
$$

where $\tau_{y(i)}^{2}=\left(E\left(Y_{(i)}\right)-\mu_{y}\right)^{2}$ and $\tau_{x y(i)}=\left(E\left(X_{[i]}\right)-\mu_{x}\right)\left(E\left(Y_{(i)}\right)-\mu_{y}\right)$.

Theorem 2: Let $Y$ has a normal distribution with the population mean $\mu_{y}$ and population variance $\sigma_{y}^{2}$. The MSE of the ratio estimator for the population mean $\mu_{y}$ in RSS when the ranking according to interest variable $Y$ is defined as follows

$\operatorname{MSE}\left(\bar{Y}_{r_{R S S(Y)}}\right)=\operatorname{MSE}\left(\bar{Y}_{r_{S R S}}\right)-\left(\rho C_{x}-C_{y}\right)^{2} \frac{\mu_{y}^{2}}{m^{2} r} \sum_{i=1}^{m} \alpha_{i: m}^{2}$

where $\alpha_{i: m}=E\left(Z_{(i)}\right)=\frac{E\left(Y_{(i)}\right)-\mu_{y}}{\sigma_{y}}$.

The proof and comments of Theorem 2 are similar to Theorem 1.

Using the MSEs given in Theorem 1 and 2, the difference between $M S E\left(\bar{Y}_{r_{R S S(X)}}\right)$ and $\operatorname{MSE}\left(\bar{Y}_{r_{R S S(Y)}}\right)$ is obtained as follows

$$
\begin{aligned}
\operatorname{MSE}\left(\bar{Y}_{r_{R S S(X)}}\right)-\operatorname{MSE}\left(\bar{Y}_{r_{R S S(Y)}}\right) & =\left[\left(\rho C_{x}-C_{y}\right)^{2}-\left(C_{x}-\rho C_{y}\right)^{2}\right] \frac{\mu_{y}^{2}}{m^{2} r} \sum_{i=1}^{m} \alpha_{i: m}^{2}, \\
& =\left[\left(C_{x}^{2}-C_{y}^{2}\right)\left(\rho^{2}-1\right)\right] \frac{\mu_{y}^{2}}{m n} \sum_{i=1}^{m} \alpha_{i: m}^{2}
\end{aligned}
$$

As seen in Eq. (19), $C_{y}, C_{x}$ and $\rho$ values should be examined to determine which variable to employ for ranking. When $C_{y}^{2}$ and $C_{x}^{2}$ are close to each other or $\rho$ is close to 1 , there is a small difference between ranking based on auxiliary and interested variables. When $C_{y}^{2}>C_{x}^{2}$ and $\rho$ value is small, the ranking according to $Y$ can be preferred. Besides, when $C_{x}^{2}>C_{y}^{2}$ and $\rho$ value is small, the ranking according to $X$ can be preferred. 


\section{Simulation Study}

In this section, Monte Carlo simulation study was performed to support the theoretical results given in Section 2. In the simulation study, data were obtained from the bivariate normal distribution for the interest variable $Y$ with the auxiliary variable $X$. The parameters of this bivariate normal distribution were determined to provide the coefficient of variations $C_{x}=0.005\left(\mu_{x}=200, \sigma_{x}=1\right), C_{y}=0.1\left(\mu_{y}=\right.$ $\left.10, \sigma_{y}=1\right)$ and $C_{x}=C_{y}=0.05\left(\mu_{x}=\mu_{y}=20, \sigma_{x}=\sigma_{y}=1\right)$. Thus, $C_{x}=C_{y}$ and $C_{x}<C_{y}$ cases were examined. In the case of $C_{x}>C_{y}\left(C_{x}=0.1, C_{y}=0.005\right)$, since the classical sample mean statistics is more efficient than the ratio estimator for the population mean in SRS [23, 24], this situation was not included in the simulation study.

Set size and cycle size are taken as $m=3,4,5,6,9,10, r=1$ and correlation coefficient is taken as $\rho=0.50,0.60,0.70,0.80,0.90,0.99$. Using these generated data, ratio estimators were obtained according to SRS and RSS designs. The simulation study was repeated 500000 times. The simulation is carried out using Matlab2007b software.

In order to compare the performance of the ratio estimators, proportional bias (PB) and relative efficiency (RE) values were calculated by obtaining the expected and MSE values of these estimators. PB values for SRS and RSS ranking by $X$ and $Y$ are calculated as follows respectively,

$$
\begin{aligned}
& P B_{(S R S)}=\frac{E\left(\bar{y}_{r_{S R S}}\right)-\mu_{y}}{\mu_{y}}, \\
& P B_{(R S S(X))}=\frac{E\left(\bar{y}_{r_{R S S(X)}}\right)-\mu_{y}}{\mu_{y}}, \\
& P B_{(R S S(Y))}=\frac{E\left(\bar{y}_{r_{R S S(Y)}}\right)-\mu_{y}}{\mu_{y}} .
\end{aligned}
$$

$R E$ values for ranking according to auxiliary and interested variables can be defined as follows:

$$
R E_{(S R S, R S S(X))}=\frac{M S E\left(\bar{Y}_{r_{S R S}}\right)}{\operatorname{MSE}\left(\bar{Y}_{r_{R S S(X)}}\right)}, \operatorname{RE} E_{(S R S, R S S(Y))}=\frac{M S E\left(\bar{Y}_{r_{S R S}}\right)}{\operatorname{MSE}\left(\bar{Y}_{r_{R S S(Y)}}\right)} .
$$

The results were given in Tables 1 and 2 . 
Table 1. $R E_{(S R S, R S S(X))}$ and $R E_{(S R S, R S S(Y))}$ values when $C_{x}<C_{y}$

\begin{tabular}{|c|c|c|c|c|c|c|c|}
\hline$\rho$ & & $n=3$ & $n=4$ & $n=5$ & $n=6$ & $n=9$ & $n=10$ \\
\hline \multirow{5}{*}{0.99} & $P B_{(S R S)}$ & -0.0001 & -0.0002 & 0.0000 & 0.0000 & -0.0006 & 0.0000 \\
\hline & $P B_{(R S S(X))}$ & -0.0001 & -0.0001 & -0.0001 & -0.0001 & 0.0000 & 0.0000 \\
\hline & $P B_{(R S S(Y))}$ & -0.0001 & -0.0001 & 0.0000 & -0.0001 & 0.0000 & 0.0000 \\
\hline & $R E_{(S R S, R S S(X))}$ & 1.8701 & 2.2652 & 2.6647 & 3.0123 & 4.1947 & 4.5590 \\
\hline & $R E_{(S R S, R S S(Y))}$ & 1.9071 & 2.3397 & 2.7690 & 3.1657 & 4.5573 & 4.9363 \\
\hline \multirow{5}{*}{0.90} & $P B_{(S R S)}$ & -0.0002 & -0.0001 & -0.0001 & 0.0000 & 0.0000 & -0.0001 \\
\hline & $P B_{(R S S(X))}$ & -0.0002 & -0.0001 & -0.0001 & 0.0000 & 0.0000 & 0.0000 \\
\hline & $P B_{(R S S(Y))}$ & -0.0001 & -0.0001 & 0.0000 & 0.0000 & 0.0000 & 0.0000 \\
\hline & $R E_{(S R S, R S S(X))}$ & 1.7187 & 2.0002 & 2.2449 & 2.3661 & 2.9102 & 3.0795 \\
\hline & $R E_{(S R S, R S S(Y))}$ & 1.9135 & 2.3562 & 2.7614 & 3.1181 & 4.4288 & 4.8785 \\
\hline \multirow{5}{*}{0.80} & $P B_{(S R S)}$ & -0.0002 & 0.0000 & 0.0000 & -0.0001 & -0.0001 & -0.0001 \\
\hline & $P B_{(R S S(X))}$ & -0.0001 & 0.0000 & 0.0000 & 0.0000 & 0.0000 & 0.0000 \\
\hline & $P B_{(R S S(Y))}$ & -0.0001 & -0.0001 & 0.0000 & 0.0000 & 0.0000 & 0.0000 \\
\hline & $R E_{(S R S, R S S(X))}$ & 1.5738 & 1.7566 & 1.9379 & 2.0531 & 2.2558 & 2.4713 \\
\hline & $R E_{(S R S, R S S(Y))}$ & 1.9055 & 2.3448 & 2.7647 & 3.1356 & 4.4428 & 4.8716 \\
\hline \multirow{5}{*}{0.70} & $P B_{(S R S)}$ & -0.0001 & -0.0001 & 0.0000 & -0.0001 & 0.0000 & -0.0001 \\
\hline & $P B_{(R S S(X))}$ & 0.0000 & 0.0000 & 0.0000 & -0.0002 & 0.0000 & -0.0001 \\
\hline & $P B_{(R S S(Y))}$ & 0.0000 & -0.0001 & 0.0000 & -0.0001 & 0.0000 & 0.0000 \\
\hline & $R E_{(S R S, R S S(X))}$ & 1.4869 & 1.6086 & 1.7199 & 1.7916 & 1.8960 & 2.0170 \\
\hline & $R E_{(S R S, R S S(Y))}$ & 1.9096 & 2.3387 & 2.7489 & 3.1396 & 4.4126 & 4.8503 \\
\hline \multirow{5}{*}{0.60} & $P B_{(S R S)}$ & -0.0001 & -0.0002 & -0.0001 & 0.0000 & 0.0000 & 0.0000 \\
\hline & $P B_{(R S S(X))}$ & 0.0000 & 0.0000 & 0.0000 & -0.0001 & 0.0000 & -0.0001 \\
\hline & $P B_{(R S S(Y))}$ & 0.0000 & 0.0000 & 0.0000 & -0.0001 & 0.0000 & 0.0000 \\
\hline & $R E_{(S R S, R S S(X))}$ & 1.3997 & 1.4673 & 1.5481 & 1.6147 & 1.6664 & 1.7286 \\
\hline & $R E_{(S R S, R S S(Y))}$ & 1.9090 & 2.3381 & 2.7567 & 3.1384 & 4.3894 & 4.8197 \\
\hline \multirow{5}{*}{0.50} & $P B_{(S R S)}$ & -0.0001 & 0.0000 & -0.0001 & 0.0000 & 0.0001 & 0.0000 \\
\hline & $P B_{(\operatorname{RSS}(X))}$ & 0.0000 & 0.0000 & -0.0001 & -0.0002 & 0.0000 & 0.0000 \\
\hline & $P B_{(R S S(Y))}$ & 0.0000 & 0.0000 & 0.0000 & -0.0001 & 0.0000 & 0.0000 \\
\hline & $R E_{(S R S, R S S(X))}$ & 1.3329 & 1.3739 & 1.4420 & 1.4868 & 1.5034 & 1.5478 \\
\hline & $R E_{(S R S, R S S(Y))}$ & 1.9128 & 2.3412 & 2.7514 & 3.1412 & 4.4069 & 4.7847 \\
\hline
\end{tabular}


Table 2. $R E_{(S R S, R S S(X))}$ and $R E_{(S R S, R S S(Y))}$ values when $C_{x}=C_{y}$

\begin{tabular}{|c|c|c|c|c|c|c|c|}
\hline$\rho$ & & $n=3$ & $n=4$ & $n=5$ & $n=6$ & $n=9$ & $\mathrm{n}=10$ \\
\hline \multirow{5}{*}{0.99} & $P B_{(S R S)}$ & 0.0000 & 0.0000 & 0.0000 & 0.0000 & 0.0000 & 0.0000 \\
\hline & $P B_{(R S S(X))}$ & 0.0000 & 0.0000 & 0.0000 & 0.0000 & 0.0000 & 0.0000 \\
\hline & $P B_{(R S S(Y))}$ & 0.0000 & 0.0000 & 0.0000 & 0.0000 & 0.0000 & 0.0000 \\
\hline & $R E_{(S R S, R S S(X))}$ & 0.9953 & 1.0032 & 0.9961 & 0.9979 & 1.0031 & 0.9969 \\
\hline & $R E_{(S R S, R S S(Y))}$ & 1.0011 & 0.9997 & 0.9983 & 1.0000 & 0.9973 & 1.0038 \\
\hline \multirow{5}{*}{0.90} & $P B_{(S R S)}$ & 0.0001 & 0.0001 & 0.0001 & 0.0001 & 0.0000 & 0.0000 \\
\hline & $P B_{(R S S(X))}$ & 0.0000 & 0.0000 & 0.0000 & 0.0000 & 0.0000 & 0.0000 \\
\hline & $P B_{(R S S(Y))}$ & 0.0001 & 0.0001 & 0.0001 & 0.0001 & 0.0000 & 0.0000 \\
\hline & $R E_{(S R S, R S S(X))}$ & 1.0363 & 1.0162 & 1.0429 & 1.0328 & 1.0225 & 1.0272 \\
\hline & $R E_{(S R S, R S S(Y))}$ & 1.0141 & 1.0320 & 1.0183 & 1.0346 & 1.0476 & 1.0313 \\
\hline \multirow{5}{*}{0.80} & $P B_{(S R S)}$ & 0.0001 & 0.0001 & 0.0001 & 0.0001 & 0.0000 & 0.0001 \\
\hline & $P B_{(R S S(X))}$ & 0.0001 & 0.0000 & 0.0000 & 0.0004 & 0.0000 & 0.0000 \\
\hline & $P B_{(R S S(Y))}$ & 0.0002 & 0.0002 & 0.0001 & 0.0001 & 0.0001 & 0.0001 \\
\hline & $R E_{(S R S, R S S(X))}$ & 1.0376 & 1.0492 & 1.0468 & 1.0569 & 1.0666 & 1.0502 \\
\hline & $R E_{(S R S, R S S(Y))}$ & 1.0486 & 1.0659 & 1.0705 & 1.0656 & 1.0768 & 1.0834 \\
\hline \multirow{5}{*}{0.70} & $P B_{(S R S)}$ & 0.0003 & 0.0002 & 0.0002 & 0.0001 & 0.0001 & 0.0001 \\
\hline & $P B_{(R S S(X))}$ & 0.0002 & 0.0001 & 0.0001 & 0.0000 & 0.0000 & 0.0000 \\
\hline & $P B_{(R S S(Y))}$ & 0.0003 & 0.0003 & 0.0003 & 0.0002 & 0.0001 & 0.0001 \\
\hline & $R E_{(S R S, R S S(X))}$ & 1.0626 & 1.0832 & 1.0941 & 1.0774 & 1.1224 & 1.1095 \\
\hline & $R E_{(S R S, R S S(Y))}$ & 1.0635 & 1.0839 & 1.0923 & 1.0881 & 1.0947 & 1.1060 \\
\hline \multirow{5}{*}{0.60} & $P B_{(S R S)}$ & 0.0004 & 0.0002 & 0.0002 & 0.0002 & 0.0001 & 0.0001 \\
\hline & $P B_{(R S S(X))}$ & 0.0002 & 0.0001 & 0.0000 & 0.0001 & 0.0000 & 0.0000 \\
\hline & $P B_{(R S S(Y))}$ & 0.0004 & 0.0003 & 0.0002 & 0.0002 & 0.0002 & 0.0002 \\
\hline & $R E_{(S R S, R S S(X))}$ & 1.0908 & 1.1000 & 1.1162 & 1.1050 & 1.1603 & 1.1665 \\
\hline & $R E_{(S R S, R S S(Y))}$ & 1.0743 & 1.1269 & 1.1111 & 1.1452 & 1.1430 & 1.1332 \\
\hline \multirow{5}{*}{0.50} & $P B_{(S R S)}$ & 0.0004 & 0.0003 & 0.0003 & 0.0002 & 0.0001 & 0.0001 \\
\hline & $P B_{(\operatorname{RSS}(X))}$ & 0.0003 & 0.0001 & 0.0001 & 0.0001 & 0.0001 & 0.0000 \\
\hline & $P B_{(R S S(Y))}$ & 0.0005 & 0.0003 & 0.0003 & 0.0003 & 0.0002 & 0.0002 \\
\hline & $R E_{(S R S, R S S(X))}$ & 1.1062 & 1.1109 & 1.1428 & 1.1360 & 1.1916 & 1.2027 \\
\hline & $R E_{(S R S, R S S(Y))}$ & 1.1029 & 1.1527 & 1.1399 & 1.1867 & 1.1719 & 1.1702 \\
\hline
\end{tabular}


As seen from Table 1, $R E_{(S R S, R S S(X))}$ ve $R E_{(S R S, R S S(Y))}$ values increase as the $n$ value increases for the same $\rho$ correlation coefficient. It is also seen that $R E_{(S R S, R S S(X))}<R E_{(S R S, R S S(Y))}$ in all cases as expected. As $\rho$ approaches 0.50 , the increase rate of $R E_{(S R S, R S S(X))}$ is lower than the increase rate of $R E_{(S R S, R S S(Y))}$ when $n$ value increases.

As $\rho$ decreases and $n$ increases, the differences between $R E_{(S R S, R S S(X))}$ and $R E_{(S R S, R S S(Y))}$ values increase. For all $\rho$ values under the same sample size, $R E_{(S R S, R S S(Y))}$ values are close to each other. For example, when $n=3$ and $\rho=0.99, R E_{(S R S, R S S(Y))}$ value is 1.9071 , similarly when $n=3$ and $\rho=0.50, R E_{(S R S, R S S(Y))}$ value is 1.9128 . Thus, it can be said that $R E_{(S R S, R S S(Y))}$ values are not affected by the value of $\rho$. When PB values are considered, it is seen that these values close to zero in all cases.

As seen from Table 2, $R E_{(S R S, R S S(X))}$ and $R E_{(S R S, R S S(Y))}$ values are approximately 1 when $\rho=0.99$. In this case, the efficiency of the $\operatorname{RSS}(X), \operatorname{RSS}(Y)$ and SRS designs are very close to each other. As $\rho$ decreases and $n$ value increases, $R E_{(S R S, R S S(X))}$ and $R E_{(S R S, R S S(Y))}$ values increase. Also PB values are close to 0 for all cases.

\section{Numerical Example}

To illustrate how one might implement the estimators given in section 2 , we used the data, which represent the weight $(Y)$ and the lenght $(X)$ of 167 fish of the Alburnus mossulensis population living in Keban Dam Lake, Elazı ğ in Turkey. They were captured between date of November 2011 and December 2012 [25]. In this example, we were interested in the estimation of the mean for fish weight using RSS. Auxiliary variable was taken as fish length in this study. The samples were ranked based on both weight and length. The correlation coefficient between weight and length was calculated as 0.8837 . This correlation is appropriate to use ratio estimator in RSS. The ratio estimation of the population mean was calculated when the unit ranking was performed based on both auxiliary variable and variable of interest in RSS. Numerical example was performed for $n=6,(m, r)=(2,3),(3,2),(6,1)$ and $n=10,(m, r)=(2,5)$, $(5,2),(10,1)$ for the $R S S$ and $S R S$ data sets. The parameter values were given in Table 3.

Table 3. Parameter values for $X$ and $Y$ variables

\begin{tabular}{ll}
\hline $\mathrm{N}=167$ & $\rho_{x y}=0.8837$ \\
$\mu_{x}=126.44$ & $\mu_{y}=12.50$ \\
$\sigma_{x}^{2}=50.5487$ & $\sigma_{y}^{2}=4.7648$ \\
$C_{x}=0.056$ & $C_{y}=0.174$ \\
\hline
\end{tabular}

The population ratio was defined by $R=\frac{\mu_{y}}{\mu_{x}}=\frac{12.50}{126.44}=0.0989$. The calculated $M S E$ values using Eq. (6), (8) and (18) and $R E$ using Eq. (23) were given in Table 4.

As can be seen in Table 4, MSE $\left(\bar{Y}_{r_{R S S(Y)}}\right)$ is smaller than $\operatorname{MSE}\left(\bar{Y}_{r_{R S S(X)}}\right)$ for the same $(m, r)$ values. However, to compare the REs of the estimators with each other, we obtained the values of $M S E$ of each estimator using the population data, both $\operatorname{MSE}\left(\bar{Y}_{r_{R S S(X)}}\right)$ and $\operatorname{MSE}\left(\bar{Y}_{r_{R S S(Y)}}\right)$ values are smaller than $\operatorname{MSE}\left(\bar{Y}_{r_{S R S}}\right)$ for the same sample size. For example, when $m=2$ and $r=3, \operatorname{MSE}\left(\bar{Y}_{r_{R S S(Y)}}\right)=0.2942$ is smaller than $\operatorname{MSE}\left(\bar{Y}_{r_{R S S(X)}}\right)=0.3437$ and when $n=m r=6$, both of them are smaller than $\operatorname{MSE}\left(\bar{Y}_{r_{S R S}}\right)=0.4232$. For the same sample size, when the set size increases, MSE values decrease for all cases. Thus, for the same sample size, a larger set size and a smaller cycle size in $R S S$ can be preferred. Moreover, $R E_{(S R S, R S S(Y))}$ values are larger than $R E_{(S R S, R S S(X))}$ for same $m$ and $r$. Besides, $R E$ values are increases as the sample size increases. Since $\rho=0.8837, R E_{(S R S, R S S(X))}$ values are also greater than 1 .

In terms of sample size, $R E_{(S R S, R S S(Y))}$ and $R E_{(S R S, R S S(X))}$ values are equal with each other for the same $m$ values $((m, r)=(2,3),(2,5))$. As can be seen in Eq. (19), the $r$ number of cycles does not affect the RE values. Besides, the maximum $R E_{(S R S, R S S(Y))}$ and $R E_{(S R S, R S S(X))}$ values are obtained for $n=10$ when $m=10$ and $r=1$. 
Since $C_{y}^{2}>C_{x}^{2}$, the ranking according to the interested variable can be preferred for this data. Besides, the difference between the MSE's is small because the $\rho$ value is 0.8837 .

Table 4. MSE and RE values of ratio estimators

\begin{tabular}{|c|c|c|c|c|c|c|c|}
\hline & $m$ & $r$ & $\operatorname{MSE}\left(\bar{Y}_{r_{S R S}}\right)$ & $\operatorname{MSE}\left(\bar{Y}_{r_{R S S(X)}}\right)$ & $\operatorname{MSE}\left(\bar{Y}_{r_{R S S(Y)}}\right)$ & $R E_{(S R S, R S S(X))}$ & $R E_{(S R S, R S S(Y))}$ \\
\hline \multirow{3}{*}{$n=6$} & 2 & 3 & \multirow{3}{*}{0.4230} & 0.3437 & 0.2942 & 1.2313 & 1.4385 \\
\hline & 3 & 2 & & 0.3040 & 0.2297 & 1.3921 & 1.8424 \\
\hline & 6 & 1 & & 0.2519 & 0.1452 & 1.6800 & 2.9146 \\
\hline \multirow{3}{*}{$n=10$} & 2 & 5 & \multirow{3}{*}{0.2539} & 0.2062 & 0.1765 & 1.2313 & 1.4385 \\
\hline & 5 & 2 & & 0.1582 & 0.0985 & 1.6049 & 2.5777 \\
\hline & 10 & 1 & & 0.1353 & 0.0615 & 1.8766 & 4.1285 \\
\hline
\end{tabular}

\section{Conclusion}

This paper indicates that using the formulas obtained in this study, MSE values can easily be calculated by utilizing the coefficients of variation when the variables have bivariate normal distribution. In addition, if there is a priori knowledge about the coefficients of variation, it can be decided to which variable can be used for ranking in $R S S$. Particularly, while it is preferred ranking according to $X$ when $C_{x}>C_{y}$ and ranking according to $Y$ is preferred when $C_{x}<C_{y}$. In addition, any of $X$ and $Y$ can be used for ranking when $C_{x}$ close to $C_{y}$. As a result of the simulation study, when $C_{x}<C_{y}$, the differences between $R E_{(S R S, R S S(X))}$ and $R E_{(S R S, R S S(Y))}$ values increase as $\rho$ decreases and $n$ increases. In this case, $R E_{(S R S, R S S(Y))}$ values are not affected by the value of $\rho$. Also when $C_{x}=C_{y}, R E_{(S R S, R S S(X))}$ and $R E_{(S R S, R S S(Y))}$ values are approximately 1 when $\rho$ close to 1 . In this case, $R E_{(S R S, R S S(X))}$ and $R E_{(S R S, R S S(Y))}$ values increase as $\rho$ decreases and $n$ value increases. As a result, $R S S$ estimators are more efficient than $S R S$ estimators for all considered cases and $R E_{(S R S, R S S(X))}$ and $R E_{(S R S, R S S(Y))}$ values increase as the set size increases for the same sample size $n$.

\section{Author's Contributions}

All authors contributed equally to the study.

\section{Statement of Conflicts of Interest}

There is no conflict of interest among the authors.

\section{Statement of Research and Publication Ethics}

The authors declares that this study complies with Research and Publication Ethics.

\section{References}

[1] Dell D.R., Clutter J.L. 1972. Ranked set sampling theory with order statistics background. Biometrics, 28: 545-555.

[2] McIntyre G.A. 1952. A method of unbiased selective sampling using ranked sets. Australian Journal of Agricultural Reseach, 3: 385-390.

[3] Takahasi K., Wakimoto K. 1968. On Unbiased Estimates of the Population Mean Based on the Sample Stratified by Means of Ordering. Annals of the Institute of Statistical Mathematics, 20: $1-31$. 
[4] Lam K., Sinha B.K., Wu Z. 1994. Estimation of parameters in two parameters exponential distribution using ranked set sample. Annals of the Institute of Statistical Mathematics, 46: 723736.

[5] Sinha Bimal K., Sinha Bikas K., Purkayastha S. 1996. On some aspects of ranked set sampling for estimation of normal and exponential parameters. Statistical Decisions, 14: 223-240.

[6] Bhoj D.S., Ahsanullah M. 1996. Estimation of parameters of the generalized geometric distribution using ranked set sampling. Biometrics, 52: 685-694.

[7] Ozturk O. 2011. Parametric estimation of location and scale parameters in ranked set sampling, Journal of Statistical Planning and Inference, 141 (4): 1616-1622.

[8] Tahmasebi S., Jafari A.A. 2014. Estimators for the parameter mean of Morgenstern type bivariate generalized exponential distribution using Rayleigh distribution revisited via ranked set sampling. Sort-Statistics and Operations Research Transactions, 38 (2): 161-179.

[9] Dey S., Salehi M., Ahmadi J. 2017. Rayleigh distribution revisited via ranked set sampling. Metron-International Journal of Statistics, 75 (1): 69-85.

[10] Ozturk O., Demirel N. 2016. Estimation of Population Variance from Multi-Ranker Ranked Set Sampling Designs. Communications in Statistics-Simulation and Computation, 45 (10): 35683583.

[11] Ozturk O., Kavlak K.B. 2018. Model based inference using ranked set samples. Survey Methodology, 44 (1): 1-16.

[12] Samawi H.M., Muttlak H.A. 1996. Estimation of ratio using rank set sampling. Biometrical Journal, 38 (6): 753-764.

[13] Ganeslingam S., Ganesh S. 2006. Ranked set sampling versus simple random sampling in the estimation of the mean and the ratio. Journal of Statistics and Management Systems, 9 (2): 459472.

[14] Al-Omari A.I., Jaber K., Al-Omari A. 2008. Modified ratio-type estimators of the mean using extreme ranked set sampling. Journal of Mathematics and Statistics, 4 (3): 150-155.

[15] Al-Omari A.I., Jemain A.A., Ibrahim K. 2009. New ratio estimators of the mean using simple random sampling and ranked set sampling methods. Investigación Operacional, 30 (2): 97-108.

[16] Kadılar C., Ünyazıc1 Y., Çıngı H. 2009. Ratio estimator for the population mean using ranked set sampling. Statistical Papers, 50 (2): 301-309.

[17] Al-Omari A.I. 2012. Ratio estimation of the population mean using auxiliary information in simple random sampling and median ranked set sampling. Statistics and Probability Letters, 82 (11): 1883-1890.

[18] Singh H.P., Tailor R., Singh S. 2014. General procedure for estimating the population mean using ranked set sampling. Journal of Statistical Computation and Simulation, 84 (5): 931-945.

[19] Ozturk O. 2018. Ratio estimators based on a ranked set sample in a finite population setting. Journal of the Korean Statistical Society, 47: 226-238.

[20] Saini M., Kumar A. 2017. Ratio estimators for the finite population mean under simple random sampling and rank set sampling. International Journal of System Assurance Engineering and Management, 8 (2): 488-492.

[21] Al-Omari A.I., Al-Nasser A. 2018. Ratio estimation using multistage median ranked set sampling approach. Journal of statistical theory and practice, 12 (3): 512-529.

[22] Stokes L.S. 1977. Ranked set sampling with concomitant variables. Commun. Statist. Theory. Meth., A6 (12): 1207-1211.

[23] Özdemir Y.A., Şahin Tekin S.T., Esin A.A. 2015. Çözümlü Örneklerle Örnekleme Yöntemlerine Giriş. Seçkin Yayınları.

[24] Cochran W.G. 1997. Sampling techniques. Third Edition, John Wiley \& Sons.

[25] Bütün S. 2013. Keban Baraj Gölü'nde Yaşayan Alburnus Mossulensis Heckel, 1843'de Otolit Biyometrisi. Yüksek Lisans Tezi, Fırat Üniversitesi, Fen Bilimleri Enstitüsü, Elazığ. 